\title{
Grade 11 Students' Proof Construction Ability in Relation to Classroom Resources
}

\author{
Benjamin Shongwe ${ }^{1^{*}}$ \\ ${ }^{7}$ Department of Mathematics Education, University of KwaZulu-Natal, Durban, SOUTH AFRICA \\ *CORRESPONDENCE: $\square$ shongweb@ukzn.ac.za
}

\begin{abstract}
Despite proof being fundamental to the mathematics discipline and its role as a means to convey mathematical content, little is known about the effect of resources on influencing students' proof construction ability. The purpose of this study was to compare two didactic environments, one regarded as resourced (favored) and the other under-resourced (disadvantaged), in relation to the construction of a mathematical proof. Motivated by the discrepancies in the literature on the influence of school resources on students' performance and the unfortunately prevalent view that the sole function of proof in mathematics is verification by using confirmatory cases, this study sought to examine the differences (if any) between resourced and under-resourced classrooms in relation to students' proof construction ability. To this end, data were drawn from a proof-related task performed by 78 Grade 11 students in the Ethekwini Metropolitan area, South Africa. A modified version of the Proof Construction Assessment tool showed that students in resourced schools significantly performed better than those in under-resourced schools in relation to proof construction. In addition, there was an observable and noticeable effect of this. Specifically, at an alpha $=.05$, the $t$-test for independent means revealed a significant difference between the two groups, $t(76)=2.749, p<.01, d=.624$ SD. The practical significance of the results emphasizes the importance of taking into account the role of resources when investigating the learning and teaching of proofs. Further, preliminary results also suggested that most students struggled to even begin to prove the proposition. Recommendations and implications for the students' careers and future research are raised and discussed.
\end{abstract}

Keywords: functional understanding of proof, school resources, dynamic geometry software

\section{INTRODUCTION}

In all past decades, a wealth of educational research has shown that proof is a notoriously difficult concept for students (Thompson, Senk, \& Johnson, 2012). Compounding this difficulty are studies that show that Learning and Teaching Support Material (hereafter LTSM) also influences the learning of proof. However, South Africa is a country wracked by rampant inequalities in economic circumstances and educational provision that has resulted in an education system characterized by two different school resource levels, one described as favored (advantaged) and the other under-resourced (disadvantaged) (Bertram \& Hugo, 2008; Soudien, 2007). For instance, although most students receive textbooks for mathematics and other subjects,

Article History: Received 12 July $2019 \bullet$ Revised 27 September $2019 \bullet$ Accepted 4 November 2019

(C) 2020 by the authors; licensee Modestum Ltd., UK. Open Access terms of the Creative Commons Attribution 4.0 International License (http://creativecommons.org/licenses/by/4.0/) apply. The license permits unrestricted use, distribution, and reproduction in any medium, on the condition that users give exact credit to the original author(s) and the source, provide a link to the Creative Commons license, and indicate if they made any changes. 
some favored schools (referred to as Dinaledi Schools ${ }^{1}$ for the purpose of this study) have been provided with both textbooks and information technology software.

Given this resource disparities across mathematics classrooms, it is only natural to ask whether school resources make any difference in the learning of proof. In addition, research on the influence of LTSM in mathematics performance has been inconclusive (Gustafsson, 2003). Therefore, researchers have yet to agree on a clear answer. To my knowledge, no study has yet examined students' proof construction ability in terms of the resourcefulness of schools. The purpose of this comparative study was to examine the differences between students attending resourced and under-resourced in terms of proof construction ability. To frame this research, a review of literature is provided. However, prior to presenting a background to the study, key terms are clarified.

By LTSM in this study is meant textbooks and information technology software including dynamic geometry software (hereafter DGS). In particular, computer applications like Geogebra and Sketchpad can be used to enculturate students into the practices of mathematicians which is characterized by experimentation, conjecturing, proving, and seeking counter-examples (de Villiers, 2004). The proving process involves argumentation. In the words of Douek (2009), ““[a]rgumentation” consists of one or more logically connected "arguments"” (p. 334). In this regard, a single proof is constituted by a constellation of these arguments. Seen in this light, a proof is a product of argumentation and proving is the activity of logically appropriating arguments to reach a conclusion. By verification is meant making sure that a mathematical conjecture is true for all cases. In validating the correctness of a mathematical proposition, an examination of whether the chain of logically connected axioms were used to arrive at a conclusion regardless of its form or aesthetic appeal, is conducted (Hanna, 2007). Another traditional approach in mathematics classrooms is to use some examples as confirmatory cases and then proceed to introduce deductive proof only as a means to verify that the conjecture being tested with examples is true and thus attain conviction. A conjecture is a proposition that is consistent with data and has not been proven to be either true or false (Uploaders, 2013). The main point here is to note that verification of a mathematical proposition can take two forms: empirical or deductive; empirical by selecting a few cases and deductive by logically connecting a set of axioms to produce a new result.

\section{BACKGROUND}

South Africa is a country wracked by rampant inequalities in economic circumstances and educational provision that has resulted in an education system characterized by two different school resource levels (Bertram \& Hugo, 2008; Soudien, 2007). In the context of public schools, a minority of resourced and successful schools are found in established urban, middle class areas (Brodie, 2006). More important for this study, Reddy et al. (2012) found that these schools are provided with library materials, audiovisual resources, information technology software, specialized teachers and have the wherewithal to employ and pay from their coffers additional teachers (over and above those paid by the government) and thus reduce student-teacher ratio, tend to perform better.

In contrast, about 85\% of under-resourced schools (Bloch, 2009; Grant, 2014) whose performance was abysmal, were found in townships, rural communities, informal settlement areas of either tin shanties erected by the people themselves or small brick houses, and on farms (Bloch, 2009; Lubben, Sadeck, Scholtz, \& Braund, 2010). In addition, these schools lack sports fields for a variety of extramural activities, equipped laboratories, library or internet access, are characterised by indigenous cultural practices such as emphasis on respect for the elders and teachers, have large class sizes, and have students whose mother tongue differed from the medium of instruction. The lack of sporting facilities makes students turn their playgrounds into rudimentary sports field (Kane-Berman, 2017).

Reddy et al. (2012) point out that where a school is located can have a substantial impact on whether its students typically are from economically and educationally advantaged home backgrounds and thus able to provide access to important additional resources such as libraries, media centres, or museums. Very little has changed in terms of resources even under the new democratically elected government, especially in previously disadvantaged schools. This evidence suggests that the promise of equal distribution of resources is yet to materialize (Sedibe, 2011). Accordingly, given real differences in schools' resource levels (Soudien, 2007), there

\footnotetext{
1 The Dinaledi Schools Initiative is a programme coordinated by the Department of Basic Education to support selected schools with LTSM (including scientific calculators and computer software programs) for mathematics and physical sciences. The ultimate aim was to increase the number of students studying mathematics and physical science in grades 10-12, especially female and historically disadvantaged students.
} 
is a significant difference in argumentation quality between students in resourced and under-resourced schools (Lubben et al., 2010). This disparity in Euclidean geometry educational experiences contributed to gaps in student achievement. Where resources are not equally distributed the inevitable consequence is inequitable access to mathematical knowledge and this does not contribute to the attempts to arrest the notoriously persistent trends of poor student performance in Euclidean geometry. Thus, assessment on resources shows that students in under-resourced schools tend to perform poorly notwithstanding attempts by policymakers to redress the conditions under which achievement gaps grows.

South Africa's public schools were previously divided into five categories called "quintiles", according to their poverty rankings based on the assumption that schools in wealthier communities were better able to raise funds and therefore required less financial support from government. According to the South African Government News Agency (2016), the Department of Basic Education (DBE) planned to introduce a twocategory system which classified schools as either no-fee paying or fee-paying effectively scrapping the system that divided schools into quintiles. The introduction of the new system is necessary owing to the fact that the quintile system has become difficult to implement as it is based on many different criteria and that in some areas, the question is whether parents could afford to pay or not (South African Government News Agency, 2016). Regardless of the system adopted by a school, its students are required to construct proofs. In the next section, the function of proof in mathematics is considered given the fact that students' lack of appreciation of the purpose of proof makes the learning of proofs meaningless (de Villiers, 1990).

\section{Functions of Proof in Mathematics}

Most students' experience of proof is in Euclidean geometry (McCrone \& Martin, 2004). In South Africa, as in many other countries, the function that proof performs is that of convincing students about the truth of a statement. Students' actual action when confronted with proving activities entails the use of empirical arguments to prove the truth of mathematical statements. This anecdotal evidence is supported by research (for example, CadwalladerOlsker, 2011; Easdown, 2012; Herbst \& Miyakawa, 2008). This conception of the function of proof as a means to merely verify the validity of mathematical statements influences their action in proving tasks (Smith, 2014). Although this conception of the function of proof is correct, proof performs many other functions in mathematics, namely, explanation, communication, discovery, and systematization (de Villiers, 1990).

\section{Verification}

A proof can be viewed as a tool to establish certainty of a conjecture, that is, verifying (making sure) that a conjecture is true for all cases. Verification denotes the removal of uncertainty by seeking, in the vocabulary of Harel and Sowder (1998), to convince or persuade someone or oneself about the validity of a conjecture. In the case of Harel (2013), he takes this idea of certainty further and claims that the "need for certainty is the natural human desire to know whether a conjecture is true-whether it is a fact" (p. 124). Therefore, empiricism is defeasible; there are historical examples where counter-examples overturned earlier generalizations. The main point here is to note that verification of a mathematical proposition can take two forms: empirical or deductive; empirical by selecting a few cases and deductive by logically connecting a set of axioms to produce a new result.

\section{Explanation}

The explanatory function of proof pertains to the provision of insight into why a proposition is true. Whereas a theorem records an important proposition about certain ideas and their relationships, its proof spells out and records how that proposition comes to be true (Herbst \& Miyakawa, 2008). Thus, a proof provides an explanation of why a proposition is true. This view is supported by Harel (2013) who reserves the term explaining for the "mental act one carries out to understand the cause for a conjecture to be true or false" (p. 128).

According to Hanna (2000), for a proof to explain, it needs to make use of well-known and well-understood properties of the mathematical objects involved. She suggests that, given that the level of conviction is directly related to understanding, a proof that explains deepens existing conviction. Mathematicians often value one proof over another on the basis of its explanatory power (CadwalladerOlsker, 2011). Explanation seems to be of greater importance than verification because when proof is viewed as a means to explain why a proposition is true substantial improvement in students' attitude towards proof appears to take place (de Villiers, 1998). 


\section{Communication}

Mathematical proof is an essential tool for the communication of mathematical thinking. One way of communicating a proof of a conjecture is to write it down for publishing to the wider mathematical community. Communication concerns sense making and transmission of socially constructed knowledge publicly - both in discourse and in writing - that is acceptable to the mathematical community.

A defining characteristic of proof is its public nature. Essentially, mathematicians communicate their results through publishing them in mathematical journals; thus, making them accessible to the public, including the mathematical community. This social aspect of proof facilitates an understanding of what counts as justification in the mathematical community and thus communicates the nature of mathematical argument. In other words, proof is a means to demonstrate the standards (criteria) for communication in mathematics.

\section{Discovery}

The discovery function of proof relates to the generation of new results (theorems) through proof. Similar to Stylianides (2009), the phrase "new results" is used to describe proof knowledge that students add to their existing knowledge base as a result of constructing a proof. Thus, by generation or creation of new mathematics relates to what students produce as new to them but may have been known to the community of mathematics scholarship. The discovery aspect within the concept of proof involves making conjectures and attempting to provide arguments to justify them. As de Villiers (1997) points out, a proof often leads to new insights which in turn lead to the discovery of new or additional properties.

\section{Systematization}

The systematization of mathematical knowledge involves the organization of results previously thought to be unrelated into the existing deductive system of axioms, major concepts (definitions) and theorems (de Villiers, 1990). According to Knuth (2002), based on his experience both as a high school teacher and as a teacher educator, many students view the many theorems that they are asked to prove as essentially independent of one another rather than as related by the underlying axiomatic system. Knuth's (2002) sentiments resonate with my own classroom experience. Worth mentioning is that this systematization function is important in that it organizes individual statements into a coherent system and exposes the underlying logical relationships between these statements.

\section{Learning and Teaching Support Material (LTSM)}

Eric Hanushek (1986, 1997), the most influential authority on the subject (Burtless, 1996), emphatically concludes that there appears to be no strong, consistent or systematic relationship between LTSM and mathematical performance. In fact, he even found that resources have a negative effect on students' performance. Therefore, according to him, resources are only tenuously related to measured performance. This conclusion has been challenged and is hotly debated by mathematics education researchers. After a reanalysis of Hanushek's evidence, Hedges, Laine, and Greenwald (1996) found that the typical relation between input and outcome was positive and large enough to have important implications for educational policy. Recently, Lee and Zuze (2011) found that the level of school resources make more of a difference in economically developing countries like South Africa than in economically developed countries. Further, Mogodi (2013) conducted a study with a focus on understanding the use of computer technology in one Dinaledi school. He found that computer technology was not key in knowledge acquisition among students in the Dinaledi schools intervention programme as envisioned by the DBE. Therefore, the role of instructional resources on proof functions is interrogated here on the basis that some of the findings could be explained from resources perspectives.

\section{Dynamic geometry software in proving}

In this study, a school with textbooks and DGS is referred to as resourced and that with only textbooks as under-resourced. The rationale for this distinction emanates from the notion that DGS tends to be useful in demonstrating the verification and discovery functions of proof (de Villiers \& Heideman, 2014). The DGS has the drag mode that makes it possible for the student to continuously experiment by varying geometric configurations so as to quickly and easily investigate the veracity of particular conjectures (de Villiers, 1998). Providing students with opportunities to use DGS allows them to observe patterns and see connections and thus support concept development in a way which would not be possible with pencil and paper (Denton, 2017). In general, the existing research is very positive about the use of DGS to support the learning of geometry (for 
example, Arzarell, Bairral, Danie, \& Yasuyuki, 2013; Jones, 2011; Ruthven, 2012). As Christou, Mousoulides, Pittalis, and Pitta-Pantazi (2004) point out, the availability of DGS in the classroom gives a new impetus on the teaching of geometry based on students' investigations and explorations.

Thus, access to DGS can motivate students to visualize, investigate, and explore geometric theorems by experimenting a multitude of examples, and then making conjectures by observing recurring patterns. According to Pandiscio (2002), DGS enables students to "understand the ideas embedded in the theorems and problems more fully than they would have understood without the aid of technology" (p. 220). Students who use DGS demonstrate improved academic performance (Sarracco, 2005). In his exploration of the nature of proof, de Villiers (2012) shows how, with the aid of DGS, students can come to an understanding of the various functions of proof in mathematics.

\section{Principles of Proof Understanding}

Numerous studies have shown that for most students (for example, Chazan, 1993; Hanna, et al., 2009; Martin, 1997), inductive arguments, that is, a collection of few cases, is proof enough that a conjecture is true. In an attempt to address students' difficulties with understanding geometric proof, Dreyfus and Hadas (1987) formulated six principles that constitute a basis for understanding geometric proof. The discussion of these principles is beyond the scope of this study save to point out that they state that:

1. A theorem has no exceptions. A mathematical statement is said to be correct only if it is correct in every conceivable instance.

2. The dual role of proof is to convince and to explain. Even 'obvious' statements have to be proved. In particular, a proof may not be built on the apparent features of a figure.

3. A proof must be general. One or more particular cases cannot prove a general statement. However, one counter-example is sufficient to refute it.

4. The assumptions of a theorem must be clearly identified and distinguished from the conclusion.

5. The converse of a correct statement is not necessarily correct.

6. Diagrams that illustrate statements have benefits and limitations. Diagrams are general representations of the statements.

\section{Gender and Mathematical Proof}

Gender is important to consider as a characteristic because, as Hofstede (1986) points out, within certain cultures there is a higher degree of differentiation and inequity between genders than others. The differences among the genders are found in schools; microcosm of society. In simple terms, the differences in gender performance in proof construction and argumentation ability may be assumed to be driven by cultural factors (for example, gender roles). Support for this approach is found in Willingham and Cole's (1997) argument that "young women [scored] higher than young men on domestic, artistic, writing, social service, and office service vocational interests and young men [scored] higher than young women on business, law, politics, mathematics, science, agriculture, athletics, and mechanical interests" (p. 178). Geary (1998) presents evidence to support the assertion that on average, it appears that women tend to be more interested in careers that involve organic matters, for example, biology and medicine as opposed to men who tend to be more inorganic matters, for example, physics and engineering. In the words of Geary (1999),

[s]exual selection (male-male competition in particular) has resulted in a greater elaboration of the cognitive and brain systems that support navigation in physical space in men than in women. One feature of these systems is an intuitive understanding of Euclidean geometry. (p. 272)

Interesting arguments have been made on this issue of gender differences in which there seems to be empirical support for the notion that the mathematical domain of Euclidean geometry seems to favor male students than female students. In addition, Healy and Hoyles (2000) found that the gender differences in the belief that empirical arguments are proof exist also among students in algebra. The source of this gender difference is assumed to be of social and occupational interests. 


\section{THE OPTIMAL RESOURCE THEORY (ORT)}

Although correlational statistical techniques were used to study the differences in the two school types in terms of resources, the use of such statistical approaches, while beneficial, also requires theoretical rationales that inform best practices (Anderson, 2015). The optimal resource theory (ORT) developed by Anderson (2015) was used to conceptualize the research questions, methodology, analysis, and interpretation of the results of this study. According to ORT, the influence of resources on students' outcomes is best understood from the perspectives of internally controlled micro-policies and micro-practices on positive student outcomes (that is, the traditional indicators of academic mastery such as grades, standardized tests, skill mastery, etc.) or personal development (that is, racial identity, moral development, self-discipline, societal awareness, etc.). In this study, the focus was on the former; students' outcomes in relation to resources. The theory espouses six principles: one chief principle and the other five which are collectively referred to as governing principles.

\section{Chief Principle}

Anderson (2015) argues that positive student outcomes relates to assessing students' incremental achievement rather than systemic change by examining micro-policies and practices which are represented by internally controlled decisions at a given local level (for example, district, school, and classroom). As a consequence, such internally controlled practices may more readily inform best-practice research. The central tenet of the ORT is that it evokes investigation of differential effects of micro-policies and micro-practices which are within the purview of the school or organization's control, with a specific focus on positive student outcomes.

\section{Governing Principles}

The first governing principle of ORT posits that multiple factors that influence student outcomes should be examined. The second governing principle focuses on including externally controlled factors (gender, class, etc.), with the intent of controlling for these factors rather than rather that considering them as de facto cause because, as Anderson (2015) points out, externally controlled factor manipulation is not a goal of ORT. While the third governing principle of ORT recognizes that nonschool-based decisions influence educational outcomes as well, it entails the manipulation of internally controlled decisions. Incremental progress comprise ORT's fourth governing principle which emphasizes the notion that reasonable outcomes rather than comprehensive change is the most important outcome to expect.

Final, the fifth ORT governing principle is the finite resource decision making; it acknowledges that schools will always operate with finite resources and therefore, rather than focus on what schools lack, ORT focuses on maximizing progress with available resources (Anderson, 2015). A summary of the theory with its guiding principles is presented in Figure 1. As already mentioned, using ORT principles, the effect of school resources related to proof construction was investigated.

To examine how LTSM influence Grade 11 students' proof construction ability, the general research question guiding this study was: What is the role of resources in two different didactic learning environment? For data collection purposes, the following sub-questions were posed:

1. How are students attending resourced schools different from those attending under-resourced schools in relation to proof construction ability?

2. Independent of whether the difference is statistically significant or not, is the size of the effect of this difference of practical significance?

Given the efforts of the new dispensation in the South African political space to reverse the inequalities among the previously disadvantaged communities in addition to the five tenets (that is, governing principles) of ORT, the role of resources on the learning of the proof concept led to expectation of some differences between Grade 11 students attending resourced and under-resourced schools in terms of proof construction ability. 


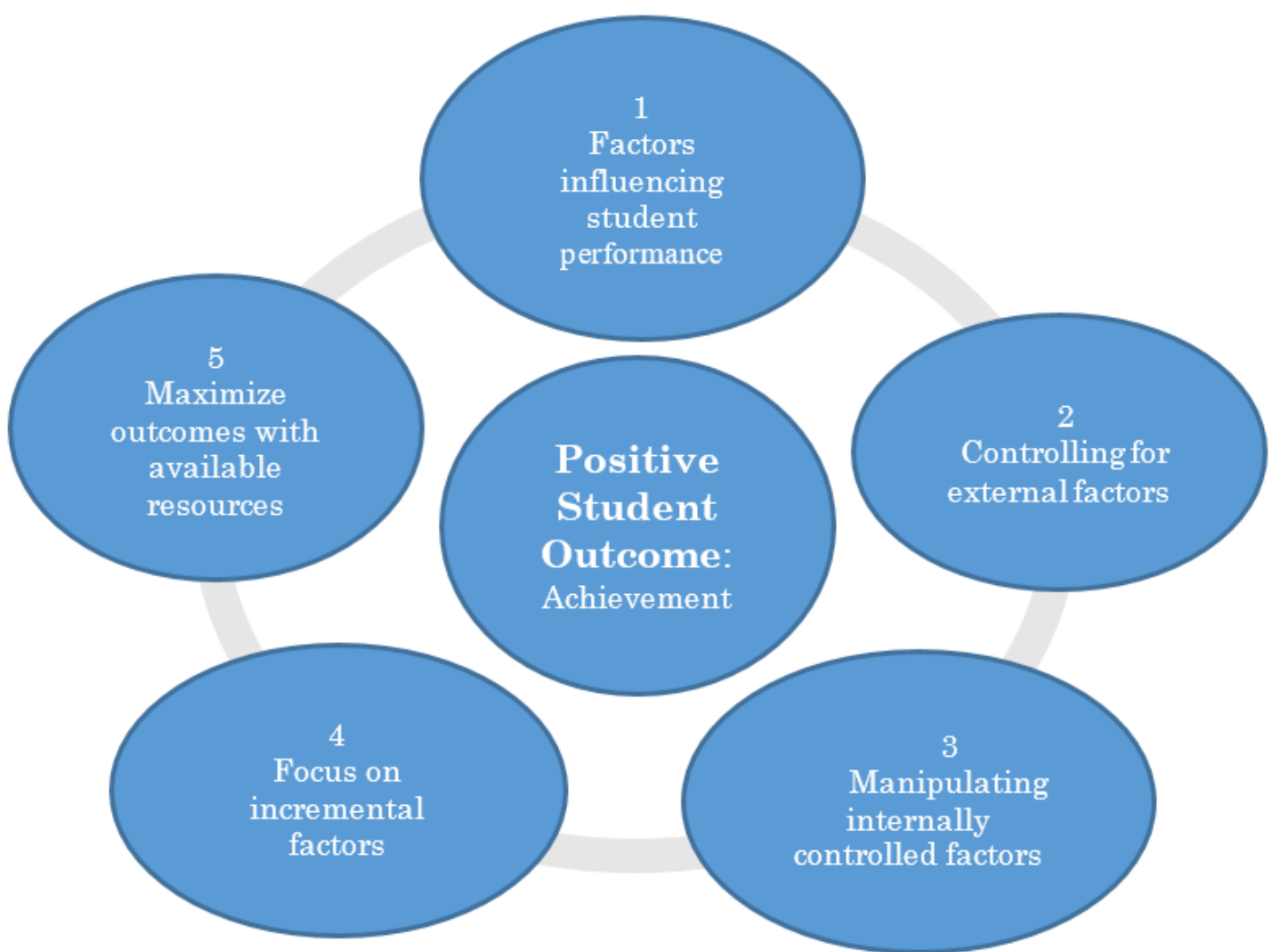

Figure 1. Optimal Resource Theory (ORT) with chief principle and governing principles. Adapted from Anderson (2015, p. 28)

\section{METHOD}

\section{Participants}

The sample in this study consisted of three components: schools, teachers, and students. Participants were 37 Grade 11 students in one mathematics classroom in a Dinaledi high school and 41 students in one mathematics classroom in a school that was outside the Dinaledi project, in the Ethekwini Metropolitan area, South Africa. The Ethekwini Metropolitan is in the KwaZulu-Natal province which is a geographical large area bordered by the Indian Ocean in the east and also shares borders with Mozambique, Swaziland, and Lesotho. The schools were representative of the general population of Dinaledi group of schools. The sociodemographic of the whole sample is depicted in Table 1.

A brief description of the two classroom environments and their corresponding practices was worth providing. In the Dinaledi school, the female teacher had been teaching for nearly 11 years and the other teacher in the nonDinaledi school for more than 15 years. The two classrooms were relatively similar in practices. Both teachers routinely followed the curriculum as reflected in the textbooks endorsed by the DBE. A typical mathematics classroom practice for both teachers included discussing previous work (mainly homework), introducing new material, and drill and practice of newly introduced concepts and terms. Seating arrangements are very important to the classroom; they may determine the extent to which interactions take place in addition to the classroom atmosphere, and student behavior. Students were seating on desks in traditional row format; they could only view other students on their sides and the back of the student in front. As depicted in Table 1, the classes were of average size. It was unsurprising therefore that these teachers were the mathematical authority in the classrooms; they were in control in the sense that they evaluated each of the students' responses and answered their own questions. A few broken windows were observed in the nonDinaledi classroom. 
Table 1. Sociodemographic Characteristics of the Sample

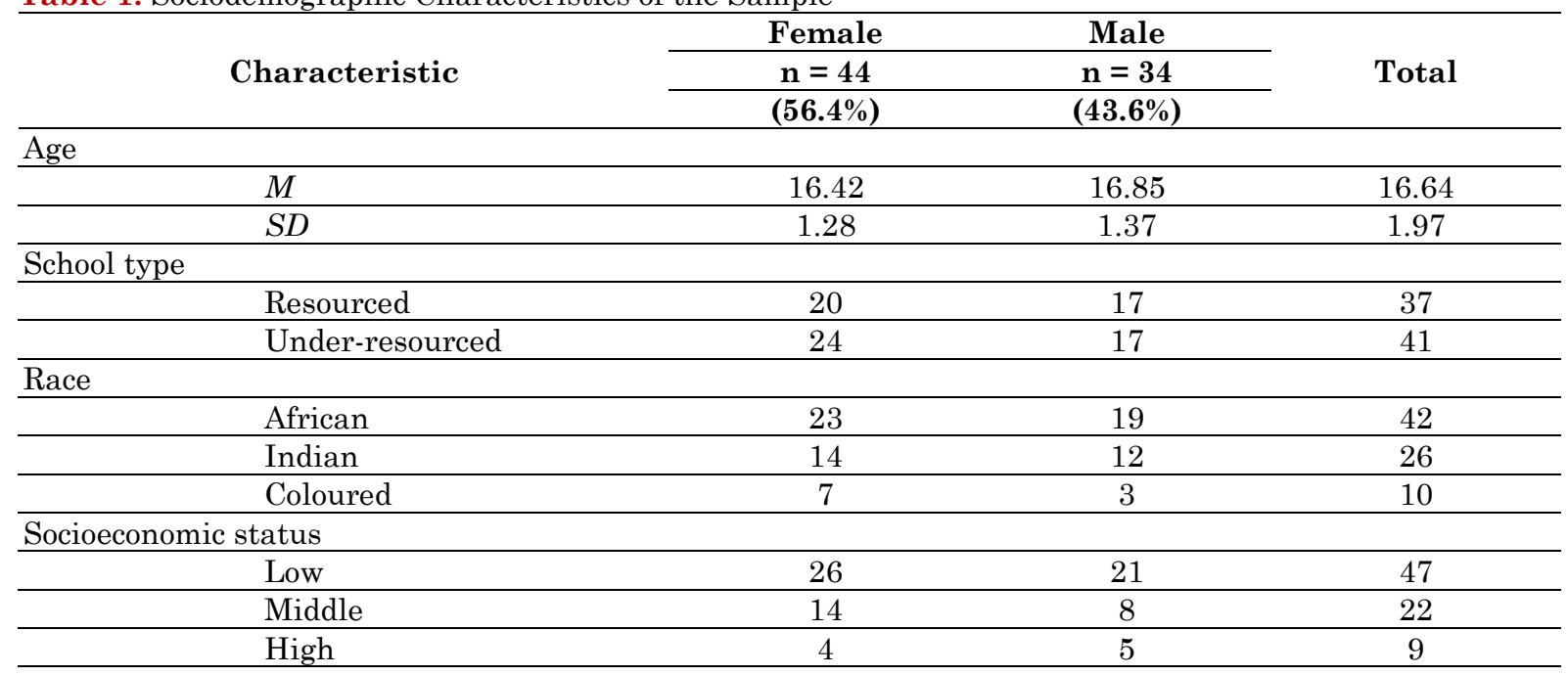

\section{Material}

A modified Proof Construction Assessment instrument was used to examine Grade 11 students' ability to do proof. McCrone and Martin's (2004) proof construction instrument revised and extended Dreyfus and Hadas' (1987) six principles that constitute a basis for understanding Euclidean proof. Briefly, the instrument involves items in which students construct partial or complete proofs (independently) in addition to generating conditional statements and local deductions. The Proof Construction Assessment instrument was designed to measure students' varying levels of ability to engage in formal logical reasoning. This measurement instrument included items with varying degrees of support to evaluate proof construction ability at four levels.

However, the focus of this study was to assess students' ability to independently construct a mathematical proof. Specifically, students were required to prove the conjecture that The angles of a triangle sum up to 180 degrees. This statement was already familiar to them because it was treated in the previous grade (10) and therefore it was expected that they believed it to be true. The rationale for focusing on Euclidean geometry is that geometry is traditionally the domain of mathematics in which students first encounter formal proofs and are required to construct them (McCrone \& Martin, 2004).

\section{Analysis of the Proof-related Task}

There are many factors influencing students' understanding of proof. Some are attitudinal and some cognitive. For instance, in school mathematics as well as in the mathematics discipline itself, a convincing argument for one person may be entirely unconvincing for another (Harel \& Sowder, 1998). The modified Proof Construction Assessment instrument (McCrone \& Martin, 2004), designed to measure students' varying levels of ability to engage in formal logical reasoning, was the basis of the analysis. In modifying the instrument, I considered the fact that there are a few consistent standards - for instance, rigor (delineating only axioms to make leaps from one statement to another to reach conclusion), generality, and logical reasoning-that are essential elements of a convincing proof (McCrone \& Martin, 2004). More precisely, students' proofs were coded in terms of five features. A sample student work in Figure 2 shows one student's (Presh N, not her real name) attempt to engage in a proving task designed to gauge their competency in proving a proposition and systematizing axioms.

If no attempt was made to solve the problem, a zero score was allocated. Attempts that merely used informal arguments (enumeration of confirmatory cases) were awarded a score of 1 . This score signifies the point that empirical arguments are the basis of gaining conviction in the truth of a statement (de Villiers, 1990). Rigor was judged by the presence of a warrant, that is, a statement that connects a claim to the data (Toulmin, 2003). The overall assessment of the generality of the proof was awarded a score of one bringing the total score to 10. A summary of the coding scheme is depicted in Table 2. 


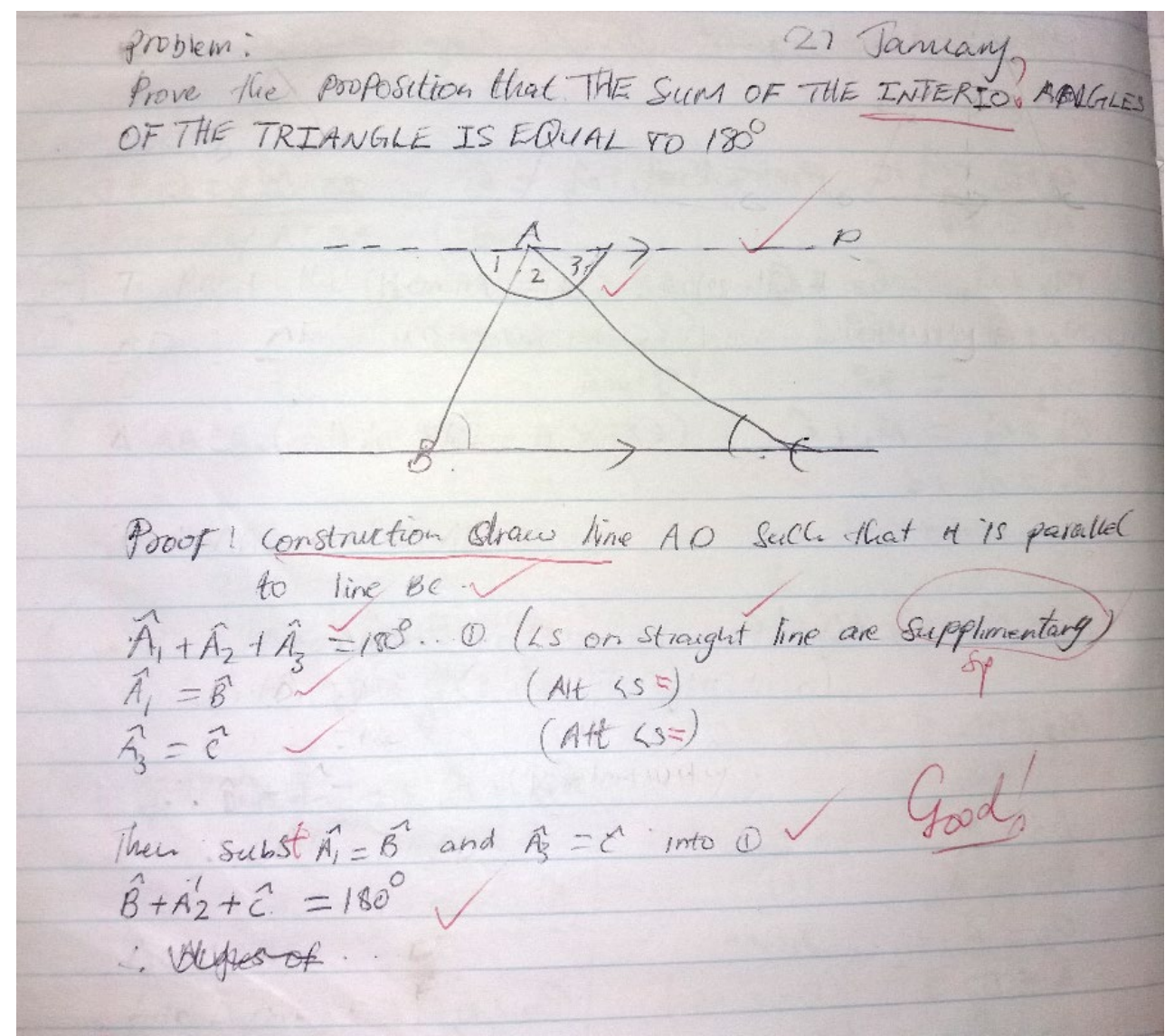

Figure 2. Presh N's (pseudonym) Proof of Proposition that "The interior angles of a triangle on a plane sum up to 180 degrees"

Table 2. The structure of LFUP questionnaire

\begin{tabular}{lc}
\hline Category & Number of items \\
\hline No attempt/idiosyncratic argument & 0 \\
\hline Inductive argument & 1 \\
\hline Rigour (claim \& justification) & 2 \\
\hline Logical connection & 1 \\
\hline Generality of proof & 1 \\
\hline
\end{tabular}

\section{RESULTS}

In this section, a preliminary analysis of the data is conducted. Then, the results are presented. Final, the interpretation of the $t$-test results is made. The SPSS v.24 (IBM Corp, Released 2016) was used to run the $t$ test to check the mean differences in students' functional understanding of proof from the resources perspective. Prior to performing an independent (separate and distinct) samples $t$-test to compare the means of these two groups of students, the data were screened for normality, missing data, and outliers.

\section{Preliminary Analysis}

The values of numerical measures of shape of the distribution (kurtosis and skewness) were within the acceptable range of -1 and +1 (Wilson \& MacLean, 2011). However, given that skewness and kurtosis are a function of sample size, further evidence in support of normality was sought. As depicted in Figure 3, using the Normal Q-Q Plot, there is no evidence of outliers and the scores are reasonably normally distributed since the point are closer to the straight line. 


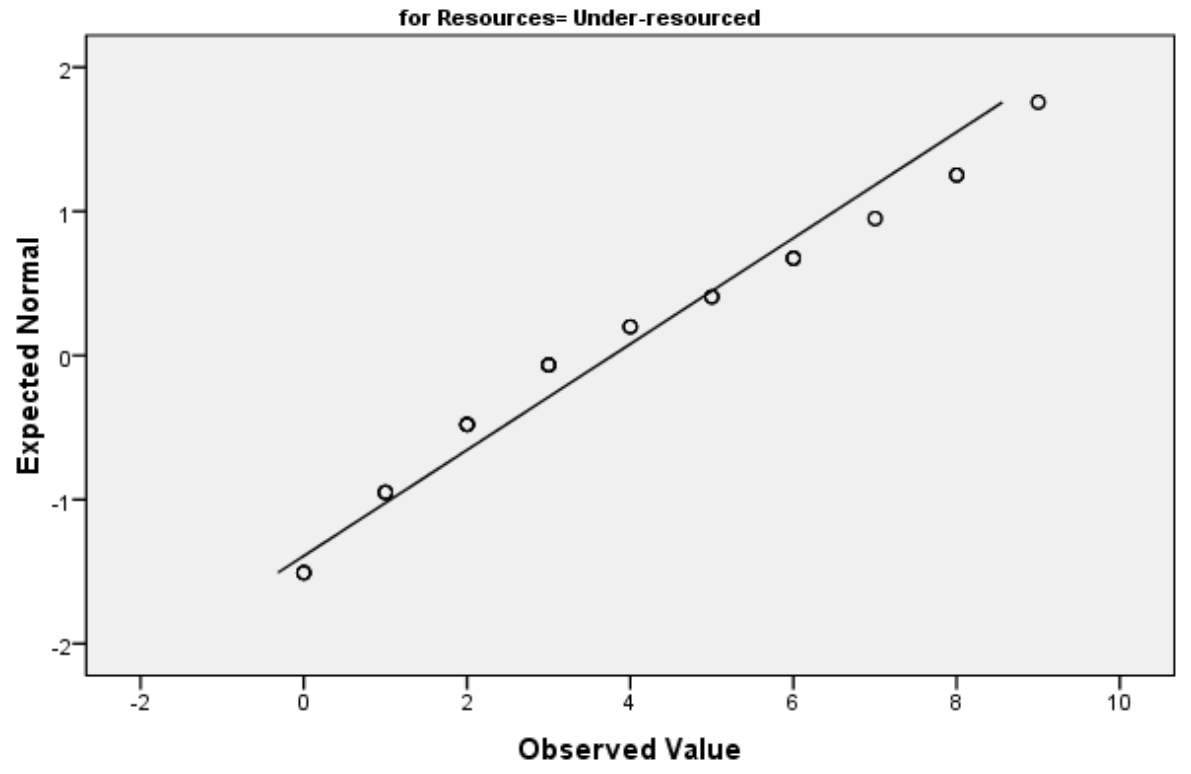

Figure 3. The Normal Q-Q Plot for normality of scores in the proof test

Table 3. The t-test for differences of means of the two groups of students

\begin{tabular}{llccccc}
\hline \multicolumn{3}{c}{ Levene's Test for Equality of Variances } & \multicolumn{3}{c}{ t-test for Equality of Means } \\
\hline & & F & Sig. & t & df & Sig. (2-tailed) \\
\hline Proof & Equal variances assumed & .209 & .649 & 2.749 & 76 & .007 \\
Construction & Equal variances not assumed & & & 2.754 & 75.654 & .007 \\
\hline
\end{tabular}

Further, the data were normally distributed and equality of variance testing of the data was examined. As explained in Table 3, given that the Levene's test indicated a non-significant result, it follows that the variances of the two populations were unequal across the two groups (that is, $p>.05$ ). Hence, the row of results (that is, equal variances assumed) was consulted. Given that these results and that the scores were ratio scaled, the data were amenable to parametric statistical analyses (Creswell, 2012). Thus, this result evoked confidence that the conclusions drawn from this $t$-test were accurate. With these preliminary analysis results in mind, I proceeded to perform a $t$-test for independent samples; the assumptions of a $t$-test were not violated.

Among Grade 11 students at the two schools $(n=78)$, there was a statistically significant difference between the students attending resourced school $(M=5.51, S D=2.82)$ and those attending an under-resourced school $(M=.78, S D=2.71)$ on proof construction ability. The differences in the comparison of students' proof construction ability were based on their responses on the proof-related task. However, it is not only important to rely on the $p$-value to know whether the difference is statistical significant, but also quantifying the strength of the conclusion on the difference between two means is equally important.

In this light, effect size was used to determine whether the difference was significant in a practical sense. The practical significance of mean scores for the two groups were examined in terms of standard deviation units. In line with Creswell's (2012) recommendation, the differences between the two means were practically significant if the effect size was .50 or above. In light of the fact that the standard deviations of the two groups were almost similar in this study, Cohen's (1988) $d$ was used to express the size of the effect in standard deviations. In this study, the effect size $d=.624$ suggested a medium effect in a practical sense. In particular, this means that the average student's proof construction ability in a resourced school was just over half standard deviations higher than a student in an under-resourced school in terms. Indeed, as found in various research studies (for example, de Villiers, 1990; Healy \& Hoyles, 2000), the other interesting result was that the use of confirmatory examples as a means to prove the truth of a mathematical statement was prevalent in high school.

In addition, $73 \%$ of the students in the resourced classroom environment were above the mean of the students in the under-resourced classroom and there was a $66 \%$ chance that a student picked at random from the resourced classroom will have a higher proof construction ability compared to a student picked at random 
Table 4. Students' performance on the proof problem

\begin{tabular}{lcc}
\hline \multirow{2}{*}{ Category } & \multicolumn{2}{c}{ Proof Assessment scores } \\
\cline { 2 - 3 } & Dinaledi classroom & NonDinaledi classroom \\
\hline No attempt/idiosyncratic argument & 10 & 15 \\
\hline Inductive argument & 6 & 14 \\
\hline Rigour (claim \& justification) & 13 & 9 \\
\hline Logical connection & 6 & 2 \\
\hline Generality of proof & 2 & 1 \\
\hline
\end{tabular}

from the under-resourced classroom (probability of superiority). Thus, this effect is observable and noticeable as between the heights of 14- and 18-year-old females. Overall, at an alpha $=.05$, the $t$-test for independent means revealed a significant difference between the two groups, $t(76)=2.749, \mathrm{p}<.01, d=.624 S D$.

\section{Proof Construction Performance}

As depicted in Table 4, the results from the proof-related task revealed that students in both classes seemed to struggle to construct a proof despite one more student being able to construct a proof in the Dinaledi class than in the nonDinaledi class. The results also show a concerning trend; most students (32\%) struggle to put together statement or claims that related to the task. Although this aspect of results was not a subject of the investigation, it provided preliminary insights into the extent to which students find proof difficult. One interpretation of this result could be that they lacked the requisite content knowledge (that is, knowledge of definitions and theorems). Future studies can be conducted to clarify this point.

\section{DISCUSSION AND CONCLUSION}

The purpose of this study was to explore the role of resources (LTSM) on Grade 11 students' functional understanding of proof in mathematics. Anderson's (2015) ORT was used as a framework for the analysis of students' proof construction ability. The findings that differences in LTSM (which are internally controlled resources) affect students' ability to construct proof provided strong and definitive evidence in favor of investing in LTSM. In other words, the infusion of LTSM in Dinaledi schools provides tangible mathematical ability to construct proof and so resources do make a difference. Given that the results were not only statistically significant but also practically significant, attention to the disparity in Euclidean geometry educational experiences indeed contributed to gaps in student achievement. Although the best-known research findings on the role of resources in the learning of mathematics seem to be at odds with each other, at least one of the conclusions must be wrong. The discussion is organized in terms of the two research questions. Consistent with the prediction of the ORT, the results showed that maximizing progress and manipulating internally controlled resources can contribute to student proof construction ability (Anderson, 2015).

The first research question was designed to determine whether students' proof construction ability differed significantly according to the didactic environment in which they found themselves. In particular, the question was: How are students attending resourced schools different from those attending under-resourced schools in relation to understanding the functions of proof? The data indicated that students in the resourced classroom tend to construct proofs better. It is such ability to construct proof that engenders the learning of mathematical content (Inglis, Mejia-Ramos, Weber, \& Alcock, 2013). Thus, it appeared especially important to gain insight into students' proof construction ability because it revealed the extent to which inductive arguments were seen as constituting mathematical proof. Similar to Hanushek $(1986,1997)$, the findings in the present study provide evidence that LTSM lead to notable gains in students' mathematical performance. Given the fact that South Africa is a developing country, these results also confirm Lee and Zuze's (2011) assertion that classroom resources matter in the learning of mathematics. In contrast, Mogodi (2013) found that LTSM (especially computer technology software) has little impact on student learning. This result is contested in that Mogodi's (2013) study investigated the effect of computer technology in mathematics in general. Specifically, in the seven research questions he posed, only one was intended to respond to effect of computer technology on mathematics learning and teaching. In addition, his study's setting was rural which involved a school that experienced intermittent network connectivity at the time.

The second research question sought to gain insight into the practical significance of this difference, independent of whether the difference was statistically significant or not. The result suggested that the variation of scores around the mean for students in the under-resourced classroom was less than that of those 
in resourced classroom. In fact, the effect size result of .624 suggested that the average student's proof construction ability in the resourced classroom was higher than that of a student in an under-resourced classroom. The modest effect notwithstanding, the influence of LTSM on students' proof construction ability was evident and therefore required attention from educational authorities responsible for Dinaledi schools. Thus, this effect suggested that there was a meaningful difference; students in favored didactic classroom environments tend to construct proofs noticeably better than those in less didactically favored classroom environments. The insight of a rocket scientist is not necessary to recognize that the results might be diluted because, probably students in resourced schools commonly come from middle class families-a variable that was excluded from this study - who can provide their children with steady access to DGS in their smartphones. One other limitation of this study was methodological; longitudinal studies may be able to provide better insight on students' proof construction ability better that the single time period covered by this study. For instance, the results may reflects other differences between the schools such as student effort which may have a stronger effect on proof construction than the proof-related task could detect.

The unique contribution of this study is that it adds to our knowledge of the role of resources by shining the spotlight specifically on the students' proof construction ability in mathematics classrooms. The findings have important implications for the participation of students in science, technology, engineering, and mathematics (STEM) careers and policymakers. Future studies can shed more light on the effect of socioeconomic status on students' attempts to see proof as a means to convey mathematical content (that is, a sense-making tool for the relationships among mathematical objects even for schools outside the Dinaledi programme). Such studies may help to clarify the seemingly conflicting findings about the effects of resources on students' ability to construct mathematical proof. In addition, the preliminary results suggested that most students lack the prerequisite content knowledge to construct a proof. Future studies can be conducted to clarify this point.

\section{ACKNOWLEDGEMENT AND FUNDING}

The research reported in this thesis was supported in part by the grant received from the University Capacity Development Programme (UCDP). Any opinions, findings, and conclusions or recommendations expressed in this thesis are those of the author and do not necessarily reflect the views of the UCDP.

\section{Disclosure statement}

No potential conflict of interest was reported by the authors.

\section{Notes on contributors}

Benjamin Shongwe - Department of Mathematics Education, University of KwaZulu-Natal, Durban, South Africa.

\section{REFERENCES}

Anderson, K. A. (2015). Introduction to optimal resource theory: A framework for enhancing student achievement. The Journal of Negro Education, 84(1), 25-39. https://doi.org/10.7709/jnegroeducation.84.1.0025

Arzarello, F., Bairral, M., Danie, C., \& Yasuyuki, I. (2013). Ways of manipulation touchscreen in one geometrical dynamic software. In E. Faggiano, \& A. Montone (Eds.), Proceedings of the 11th International Conference on Technology in Mathematics Teaching (pp. 59-64). Bari: University of Bari.

Bertram, C., \& Hugo, W. (2008). Social justice through epistemological access: A tale of two classrooms. In A. Muthukrishna (Ed.), Educating for social justice and inclusion in an African context: Pathways and transitions (pp. 133-143). New York: Nova.

Bloch, G. (2009). The toxic mix. What's wrong with South Africa's schools and how to fix it. Cape Town: Tafelberg. https://doi.org/10.1016/j.tox.2009.04.005

Brodie, K. (2006). Teaching mathematics for equity: Learner contributions and lesson structure. African Journal of Research in SMT Education, 10(1), 13-24. https://doi.org/10.1080/10288457.2006.10740590

Burtless, G. (Ed.). (1996). Does money matter? The effect of school resources on student achievement and adult success. Washington, D.C.: Brookings Institution Press. 
CadwalladerOlsker, T. (2011). What do we mean by mathematical proof? Journal of Humanistic Mathematics, 1(1), 33-60. https://doi.org/10.5642/jhummath.201101.04

Chazan, D. (1993). High school geometry students' justification for their views of empirical evidence and mathematical proof. Educational Studies in Mathematics, 24(4), 359-387. https://doi.org/10.1007/BF01273371

Christou, C., Mousoulides, N., Pittalis, M., \& Pitta-Pantazi, D. (2004). Proofs through exploration in dynamic geometry environments. Proceedings of the 28th Conference of the International Group for the Psychology of Mathematics Education, 2, 215-222. https://doi.org/10.1007/s10763-004-6785-1

Cohen, J. (1988). Statistical power analysis for the behavioral sciences (2nd ed.). Hillsdale, NJ: Lawrence Erlbaum Associates.

Creswell, J. W. (2012). Educational research: Planning, conducting, and evaluating quantitative and qualitative research (4th ed.). Boston, MA: Pearson Education.

de Villiers, M. D. (1990). The role and function of proof in mathematics. Pythagoras, 24, 17-24.

de Villiers, M. D. (1997). The role of proof in investigative, computer-based geometry: Some personal relections. In J. R. King, \& D. Schattschneider (Eds.), Geometry turned on! (pp. 15-24). Washington: MAA. Retrieved from http://frink.michighway.com/ dynamicm/joint-AMS-MAA.pdf

de Villiers, M. D. (1998). An alternative approach to proof in dynamic geometry. In R. Lehrer, \& D. Chazan (Eds.), Designing learning environments for developing understanding of geometry and space (pp. 369393). Mahwah, NJ: Lawrence Erlbaum.

de Villiers, M. D. (2004). Using dynamic geometry to expand mathematics teachers' understanding of proof. International Journal of Mathematical Education in Science and Technology, 35(5), 703-724. https://doi.org/10.1080/0020739042000232556

de Villiers, M. D. (2012). Rethinking proof with the Geometer's Sketchpad (Vol. 5). Emeryville, CA: Key Curriculum Press.

de Villiers, M. D., \& Heideman, N. (2014). Conjecturing, refuting and proving within the context of dynamic geometry. Learning and Teaching Mathematics, 17, 20-26.

Denton, J. (2017). Transforming mathematics: Using dynamic geometry software to strengthen understanding of enlargement and similarity. Warwick Journal of Education, 1, 69-84.

Douek, N. (2009). Approaching proof in school: From guided conjecturing and proving to a story of proof construction. In F.-L. Lin, F.-J. Hsieh, G. Hanna, \& M. de Villiers (Eds.), Proceedings of the ICMI Study 19 Conference: Proof and proving in Mathematics Education (pp. 142-147). Taipei, Taiwan: National Taiwan Normal University.

Dreyfus, T., \& Hadas, N. (1987). Euclid may stay-and even be taught. In M. M. Lindquist, \& A. P. Shulte (Eds.), Learning and teaching geometry, K-12 (pp. 47-58). Reston, VA: National Council of Teachers of Mathematics.

Easdown, D. (2012). The role of proof in mathematics teaching and the Plateau Principle. Proceedings of The Australian Conference on Science and Mathematics Education (formerly UniServe Science Conference), (pp. 28-33).

Geary, D. C. (1998). Male, female: The evolution of human sex differences. Washington, DC: American Psychology Association. https://doi.org/10.1037/10370-000

Geary, D. C. (1999). Sex differences in mathematical abilities: Commentary on the math-fact retrieval hypothesis. Contemporary Educational Psychology, 24, 267-274. https://oi.org/10.1006/ceps.1999.1007

Grant, C. C. (2014). Leading for social justice in South African schools: Where have all the activists gone? In I. Bogotch, \& C. M. Shields (Eds.), International handbook of educational leadership and social (in)justice (pp. 521-541). Springer. https://doi.org/10.1007/978-94-007-6555-9_29

Greenwald, R., Hedges, L. V., \& Laine, R. D. (1996). The effect of school resources on student achievement. Review of Educational Research, 66(3), 361-396. https://doi.org/10.3102/00346543066003361

Gustafsson, J.-E. (2003). What do we know about effects of school resources on educational results? Swedish Economic Policy Review, 10, 77-110.

Hanna, G. (2000). Proof, explanation and exploration: An overview. Educational Studies in Mathematics, 44, 5-23. https://doi.org/10.1023/A:1012737223465 
Hanna, G. (2007). The ongoing value of proof. In P. Boero (Ed.), Theorems in school: From history, epistemology and cognition to classroom practice (pp. 3-18). Rotterdam: Sense. https://doi.org/10.1163/9789087901691_002

Hanna, G., de Villiers, M. D., Arzare, F., Dreyfus, T., Durand-Guerrier, V., Jahnke, H. N., ... Yevdokimov, O. (2009). Proof and proving in mathematics education: Discussion document. In F.-L. Lin, F.-J. Hsieh, \& M. de Villiers (Eds.), Proceedings of the ICMI Study 19 Conference: Proof and proving in mathematics education. National Taiwan Normal University in Taipei, Taiwan, May 10 to May 15 (pp. xix-xxx).

Hanushek, E. A. (1986). The economics of schooling: Production and efficiency in public schools. Journal of Economic Literature, 24, 1141-1117.

Hanushek, E. A. (1997). Assessing the effects of school resources on student performance: An update. Education Evaluation and Policy Analysis, 19(2), 141-164. https://doi.org/10.3102/01623737019002141

Harel, G. (2013). Intellectual need. In K. R. Leatham (Ed.), Vital directions for mathematics education research (pp. 119-151). New York, NY: Springer. https://doi.org/10.1007/978-1-4614-6977-3_6

Harel, G., \& Sowder, L. (1998). Students' proof schemes: Results from exploratory studies. Issues in Mathematics Education, 7, 234-283. https://doi.org/10.1090/cbmath/007/07

Healy, L., \& Hoyles, C. (2000). A study of proof conceptions in algebra. Journal for Research in Mathematics Education, 31(4), 396-428. https://doi.org/10.2307/749651

Herbst, P. G., \& Miyakawa, T. (2008). When, how, and why prove theorems? A methodology for studying the perspective of geometry teachers. ZDM Mathematics Education, 40, 469-486. https://doi.org/10.1007/s11858-008-0082-3

Hofstede, G. (1986). Cultural differences in teaching and learning. International Journal of Intercultural Relations, 10, 301-320. https://doi.org/10.1016/0147-1767(86)90015-5

IBM Corp. (Released 2016). IBM SPSS Statistics for Windows, Version 24.0. Armonk, NY: IBM Corp.

Inglis, M., Mejia-Ramos, J. P., Weber, K., \& Alcock, L. (2013). On mathematicians' different standards when evaluating elementary proofs. Topics in Cognitive Science, 5, 270-282. https://doi.org/10.1111/tops.12019

Jones, K. (2011). The value of learning geometry with ICT: Lessons from innovative educational research. In A. Oldknow, \& C. Knights (Eds.), Mathematics education with digital technology (pp. 39-45). London: Continuum.

Kane-Berman, J. (2017). Achievement and enterprise in school education. Johannesburg, South Africa: South African Institute of Race Relations.

Knuth, E. J. (2002). Teachers' conceptions of proof in the context of secondary school mathematics. Journal of Mathematics Teacher Education, 61-88. https://doi.org/10.1023/A:1013838713648

Lee, V. E., \& Zuze, T. L. (2011). School resources and academic performance in Sub-Saharan Africa. Comparative Education Review, 55(3), 369-397. https://doi.org/10.1086/660157

Lubben, F., Sadeck, M., Scholtz, Z., \& Braund, M. (2010). Gauging students' untutored ability in argumentation about experimental data: A South African case study. International Journal of Science Education, 32(16), 2143-2166. https://doi.org/10.1080/09500690903331886

Martin, T. S. (1997). Calculus students abilities to solve geometric related rate problems and their understanding of related geometric growth factors (Unpublished doctoral dissertation), Boston University, Boston, MA.

McCrone, S. M., \& Martin, T. S. (2004). Assessing high school students' understanding of geometric proof. Canadian Journal of Science, Mathematics and Technology Education, 4(2), 223-242. https://doi.org/10.1080/14926150409556607

Mogodi, T. K. (2013). The use of ICT for learning at a Dinaledi school in the Limpopo province (Unpublished masters dissertation), University of Johannseburg, South Africa.

Pandiscio, E. A. (2002). Exploring the link between preservice teachers' conception of proof and the use of dynamic geometry software. School Science and Mathematics, 102(5), 216-221. https://doi.org/10.1111/j.1949-8594.2002.tb18144.x

Reddy, V., Prinsloo, C., Visser, M., Arends, F., Winnaar, L., Rogers, S., . . Mthethwa, M. (2012). Mathematics and science achievement of South African schools in TIMSS 2011. South Africa: HSRC Press. 
Ruthven, K. (2012). The didactical tetrahedron as a heuristic for analysing the incorporation of digital technologies into classroom practice in support of investigative approaches to teaching mathematics. ZDM, 44(5), 627-640. https://doi.org/10.1007/s11858-011-0376-8

Sarracco, L. (2005). The effects of using dynamic geometry software in the middle school classroom. EDT 896 Research Report, Iona College, NY. Retrieved May 21, 2019

Sedibe, M. (2011). Inequality of access to resources in previously disadvantaged South African high schools. Journal of Social Sciences, 28(2), 129-135. https://doi.org/10.1080/09718923.2011.11892937

Smith, K. (2014). How teacher beliefs about mathematics affect student beliefs about mathematics. Honors Theses and Capstones, University of New Hampshire.

Soudien, C. (2007). The "A" factor: Coming to terms with the question of legacy in South African education. International Journal of Educational Development, $182-193$. https://doi.org/10.1016/j.ijedudev.2006.07.006

South African Government News Agency. (2016). Motshekga moots scrapping of quintile system. Pretoria: South African Government News Agency. Retrieved on January 23, 2017, from http://www.sanews.gov.za/south-africa/motshekga-moots-scrapping-quintile-system

Thompson, D. R., Senk, S. L., \& Johnson, G. J. (2012). Opportunities to learn reasoning and proof in high school mathematics textbooks. Journal for Research in Mathematics Education, 3, 253-295. https://doi.org/10.5951/jresematheduc.43.3.0253

Toulmin, S. E. (2003). The uses of argument (Updated Edition). Cambridge: Cambridge University Press. https://doi.org/10.1017/CB09780511840005

Uploaders. (2013). Siyavula: Mathematics (Grade 11). Retrieved on January 23, 2016, from http://www.everythingmaths.co.za/maths/grade-11/siyavula-mathematics-grade-11-caps

Willingham, W. W., \& Cole, N. S. (1997). Gender and fair assessment. Mahwah, NJ: Erlbaum.

Wilson, S., \& MacLean, R. (2011). Research methods and data analysis for psychology. Berkshire: McGaw-Hill. 